1 Title: Competing Values Framework: a useful tool to define the Predominant Culture

2 in a Maternity Setting in Australia

3 Abstract

4 Objective: To identify the predominant culture of an organisation which could then assess

5 readiness for change.

6 Design: An exploratory design using the Competing Values Framework (CVF) as a self-

7 administered survey tool.

8 Setting: The Maternity Unit in one Australian metropolitan tertiary referral hospital.

9 Subjects: All 120 clinicians (100 midwives and 20 obstetricians) employed in the maternity

10 service were invited to participate; $26 \%$ responded.

11 Main Outcome Measure: The identification of the predominant culture of an organisation to

12 assess readiness for change prior to the implementation of a new policy.

13 Results: The predominant culture of this maternity unit, as described by those who

14 responded to the survey, was one of hierarchy with a focus on rules and regulations and

15 less focus on innovation, flexibility and teamwork. These results suggest that this unit did not

16 have readiness to change.

17 Conclusion: There is value in undertaking preparatory work to gain a better understanding

18 of the characteristics of an organisation prior to designing and implementing change. This

19 understanding can influence additional preliminary work that may be required to increase 
20 the readiness for change and therefore increase the opportunity for successful change. The

21 CVF is a useful tool to identify the predominant culture and characteristics of an

22 organisation that could influence the success of change.

23 Key words: organisation, culture assessment, change readiness, competing values

25 Background and Context for the study

\begin{tabular}{|c|c|}
\hline \multicolumn{2}{|l|}{ Summary of Relevance } \\
\hline Problem or Issue & $\begin{array}{l}\text { Implementation of significant change in healthcare can be } \\
\text { challanging. }\end{array}$ \\
\hline What is already known & $\begin{array}{l}\text { Prior to the implementation of innovations in health care } \\
\text { settings, there is often little consideration of the cultural } \\
\text { characteristics of the organisation that may determine their } \\
\text { readiness to change. }\end{array}$ \\
\hline What this paper adds & $\begin{array}{l}\text { This paper describes a methodology to determine the } \\
\text { predominant culture using the Competing Values } \\
\text { Framework. The assessment process at the study site } \\
\text { revealed characteristics that would need to be considered if } \\
\text { change was to be effective and sustainable. This process } \\
\text { can assist in change management strategies. }\end{array}$ \\
\hline
\end{tabular}

26 This paper describes the process that one maternity service undertook to gain a better

27 understanding of the predominant culture and characteristics of the organisation prior to the

28 implementation of a mandatory government policy. 
30 The effectiveness of implementing innovations in healthcare was the focus of an important

31 systematic review in $2004^{1}$. The review confirmed that prior to implementation of innovations

32 in health care settings there was often little consideration of the characteristics of the

33 organisation that may determine their readiness to change. Failure to recognise or

34 understand the organisational characteristics has been described as the root cause of the

35 mediocre success of programs designed for quality improvement in diverse disciplines ${ }^{2-9}$.

36 The literature warns of the consequences of not assessing the powerful influence of

37 organisational cultural on efforts to bring about change $6,10,11$

38 The focus of change processes is often on the practical and material change requirements.

39 The less visible and tacit characteristics of the people who will be involved in the change are

40 often over looked ${ }^{12-14}$. These characteristics include participants' self-efficacy, the

41 congruence between values and attitudes of the individual and the organisation, the

42 personal and organisational valence, the leadership style and support and the perception of

43 the value of the proposed change ${ }^{2,3,15-18}$.

44 The impetus for assessing the readiness for change in one maternity service was the

45 mandatory implementation of a government policy that would require significant adjustments

46 in order to meet the key deliverables? In this paper we will use this policy as an example to

47 demonstrate why examination of the organisation may be beneficial as preparatory work. 
48 In 2010, the government of New South Wales (NSW), Australian, issued a public health

49 policy, "Maternity - Towards Normal Birth" ${ }^{19}$. The policy required all NSW public maternity

50 services to implement strategies to reduce a range of potentially unnecessary interventions

51 in birth. Target measures were to be achieved over a five-year period, with each health

52 service accountable for outcomes. For a majority of the services this was the first time such

53 targets had been set and it was recognised that this would require a significant

54 reorganisation of systems to achieve improvements. For example, the target for women

55 having a vaginal birth after a previous caesarean section (CS) operation was set at greater

56 than $60 \%$ and in 2010 the State average was $12 \%$ (range $2.9-26 \%{ }^{20}$. At the research site

57 the success rate of vaginal birth after CS in 2010 was $12 \%$. Therefore, a five-fold

58 improvement in current practices would need to occur to achieve the target outcomes.

59 In addition, outcome data in Australia demonstrates variations in intervention rates in

60 childbirth that cannot be explained by either the demographics or clinical history of the

61 women ${ }^{21,22}$. This literature suggests that the context and cultural characteristics of

62 organisations may influence intervention in birth, rather than the clinical variables of the

63 woman or her baby. Possible explanations for variations that have been cited in the literature

64 are the effectiveness of collaboration between care providers and aspects of team work. ${ }^{23-}$

$65{ }^{30}$. The evidence suggests there is a direct link between teamwork and patient outcomes

66 including mortality rates ${ }^{31}$. Where there is effective interprofessional collaboration, based on 
67 mutual trust and respect with shared decision making and engagement at all levels, the

68 quality and safety of care is improved ${ }^{32-35}$.

69 In accepting this to be the case, gaining a better understanding of the characteristics of the

70 organisation and using this information to facilitate the development of strategies for change

71 may have a positive impact on the success rate overall and including the mandated

72 government policy. The policy requires a reduction in the overall intervention rates which

73 could be achieved through work focused on work place culture, rather than exclusively on

74 the development of practices and procedures.

\section{Study Location}

76 The research site for this study was an Australian, tertiary level, maternity service in a major

77 city. The service cares for around 2,500 women and babies per year; employs 120 obstetric

78 and midwifery clinicians and is a major teaching hospital, affiliated with two universities.

\section{Study Design and Methods}

80 An exploratory design using a self-administered, staff survey was used. Ethical approval for

81 the study was provided by the New South Wales Health Human Research Ethics Committee

82 (0911-313M), as part of a larger study investigating a change management process in the

83 maternity service.

\section{Competing Values Framework (CVF)}


85 The tool selected to assess the culture of the organisation and its readiness for change was

86 the CVF. This is a validated instrument that has been described in the literature in over 1000

87 studies, across disciplines, to describe the typology of organisational culture ${ }^{18}$.

88 The results of a systematic review ${ }^{36}$ of the instruments available for cultural assessment

89 specifically suitable for healthcare services was used to select the most appropriate

90 instrument for use in this study; the Competing Values Framework. This instrument had the

91 strength of examining the values and beliefs of the participants that informed their opinions

92 about their working environment. CVF was also cited as the most frequently used to

93 measure organisational culture in health services research ${ }^{37}$

\section{Description of the CVF}

96 The CVF was developed empirically in the early 1980s based on Jung's model of

97 psychological archetypes and research on indicators for organisational effectiveness ${ }^{18}$. The

98 framework has a typological design that identifies four types of cultures that exist within an

99 organisation: Clan, Adhocracy, Hierarchy and Market with each describing the values, basic

100 assumptions and attributes that are recognised within a team or organisation.

101 Each of the culture types are described as follows by Cameron et al (Table 1) with the 102 competing values in opposite quadrants of the table and hence the origin of the name of the

103 framework. 


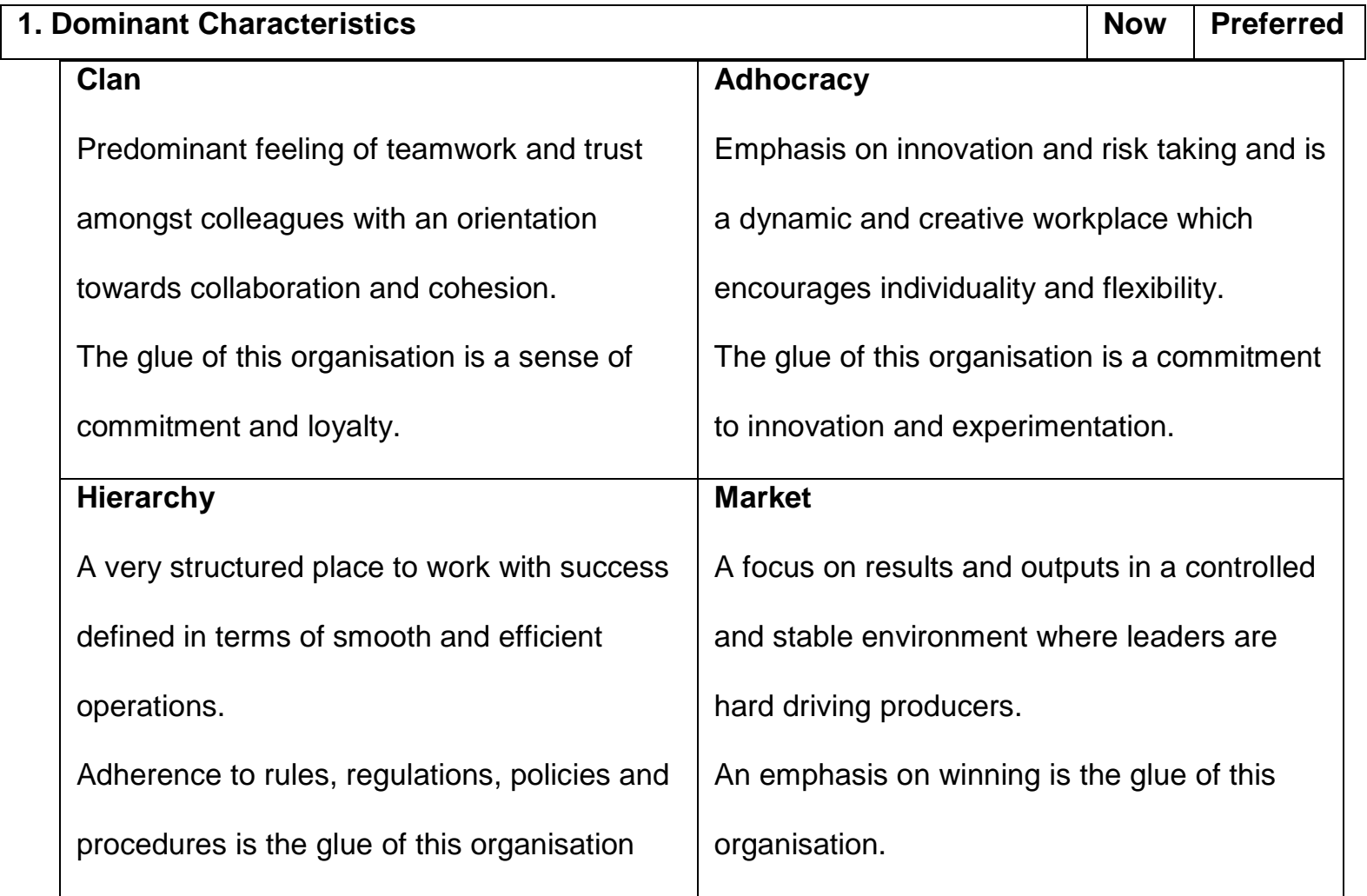

105 The predominant culture is determined by the participants' rating of six specific dimensions

106 of the organisation: the dominant characteristics, organisational leadership, management of

107 employees, organisational glue, strategic emphasis and the criteria of success. There are

108 four descriptors for each of the six dimensions and the participant provides a score in rank

109 order of preference. The options are listed as A, B, C and D and the responses provide an

110 indication of the culture type: $A=C$ lan, $B=A d h o c r a c y, C=$ Market and $D=$ Hierarchy for each

111 dimension as described in Table 2 for the dimension of "Dominant Organisational

112 Characteristics. 


\begin{tabular}{|l|l|c|c|}
\hline A. & $\begin{array}{l}\text { The Maternity Service is a very personal place. It is like an extended } \\
\text { family. People seem to share a lot of themselves }\end{array}$ & $\mathbf{1 0}$ & $\mathbf{4 0}$ \\
\hline B. & $\begin{array}{l}\text { The Maternity Service is a very dynamic and entrepreneurial place. } \\
\text { People are willing to stick their necks out and take risks }\end{array}$ & $\mathbf{2 0}$ & $\mathbf{3 0}$ \\
\hline C. & $\begin{array}{l}\text { The Maternity Service is very results-orientated. A major concern is with } \\
\text { getting the job done. People are very competitive and achievement- } \\
\text { orientated. }\end{array}$ & $\mathbf{4 0}$ & $\mathbf{2 0}$ \\
\hline D. & $\begin{array}{l}\text { The Maternity Service is very a controlled and structured place. Formal } \\
\text { procedures generally govern what people do. }\end{array}$ & $\mathbf{3 0}$ \\
\hline & \multicolumn{1}{|c|}{ Total } & 100 & $\mathbf{1 0 0}$ \\
\hline
\end{tabular}

115 Although not explicitly described in words, the responses to the dimensions assess

116 characteristics of the organisation that include congruence of values between the individual

117 and the organisation, the perception of individual value of participants' in the organisation

118 and their self-efficacy (or how effective the individual believes they can be).

119 The participant is invited to divide 100 points between each option in rank order providing

120 the highest score to the descriptor that best fits their impression of the organisation as it is

121 today. After completing the scores relevant to "now", the participant is invited to score how

122 they would "prefer" the organisation to be in five years if there was to be successful change.

123 A summative calculation of the scores is performed using the Organisational Cultural

124 Assessment Instrument (OCAI) ${ }^{18}$. The results are then graphically represented in a table

125 divided into four quadrants, one for each culture type. The final graph provides a visual

126 representation of the results which is intuitively appealing and has greater explanatory value

127 than written descriptors. The predominant culture can be identified at a glance. Specific 
128 attention should be given to where the difference between the scores for now and the

129 preferred is greater than ten points ${ }^{18}$.

130 The design of the tool facilitates an overall assessment of the predominant culture, as well

131 as assessment of the individual dimensions. This information is valuable if the organisation

132 wishes to scrutinise potential areas for change that will result in an overall cultural shift.

133 Identification of the current culture type and the preferred type is also essential for change

134 management. Where there is significant divergence in the desired predominant culture types

135 there can be variation in perceptions in espoused values, aspirations and direction ${ }^{18}$. The

136 energy, motivation and engagement by members of the organisation can be affected by this

137 incongruence and risks the organisation's ability to achieve the desired change ${ }^{18}$. The

138 degree of incongruence provides an indication of the readiness of the organisation to

139 undergo change. In addition, there is an indication of which dimensions of the organisation

140 may require the most attention for the change to be implemented successfully.

141 Administration of the CVF Tool

142 The tool was tested at a local university prior to implementation at the study site and minor

143 amendments made. The university students and academic staff recommended that the

144 scores should be out of 10 rather than 100 for greater ease of division for nominating a

145 score. Communication with the authors of the Competing Values Framework provided

146 reassurance that changing the scoring in the proposed manner may alter the variance in 
147 scores but would not make a difference to the reliability of the sum scores. The authors were

148 supportive of customising the format for the users' preference.

149 For the purpose of the research some of the language in the descriptors was changed to

150 better fit the context of a maternity service. For example, "the organisation" was changed to

151 "the Maternity Service". The amendments were not considered to change the meaning of the

152 questions but rather described in language that would have greater face validity for the

153 participants.

154 Clinicians were informed of the proposed survey at strategic opportunities such as education sessions and scheduled multidisciplinary forums. As all clinicians (100 midwives and 20

156 obstetricians) were to be invited to complete the tool, one hundred and twenty CVF tools

157 were printed on distinguishable purple paper. The majority of clinicians received this in

158 person from the researcher. Some forms were provided to the midwifery managers in each

159 of the clinical areas to reach clinicians working on evening shifts and weekends. Survey

160 boxes were placed in all clinical areas and clinicians were invited to post the completed form

161 which was conducted over a four-week period.

162 The front page of the tool described the purpose of the survey and instructions for

163 completion. In addition to the survey, demographic information about the participant was

164 collected that indicated the discipline (midwifery or obstetric), age, predominant area of 
165 practice (antenatal, birth, postnatal) and length of time employed in the service. The survey

166 was anonymous.

\section{Results}

168 Of the 120 surveys distributed 31 were returned (25.8\%). Four of the 20 Obstetricians (20\%)

169 responded and 27 of the midwives (27\%). The largest group of participants were clinical

170 midwives (71\%). The majority of the participants had been working within the organisation

171 for 1 - 5years (42\%) and were aged between 40-50 years (Table 4).

172 Table 3 Demographic Characteristics of Participants

173
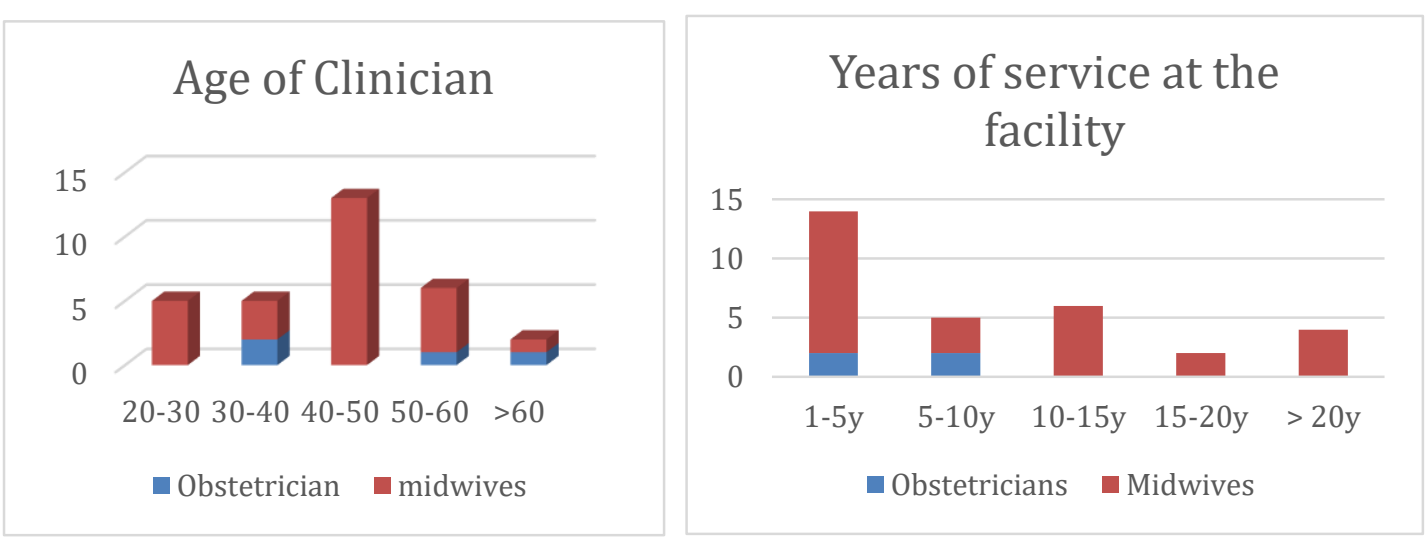

174 The survey respondents described the predominant culture of their organisation as one of

175 Hierarchy with a focus on Market (Figure 1). They identified that the prevalence of teamwork

176 and collaboration was low and of even less prevalence was a culture that encouraged

177 innovation and flexibility. Respondents expressed their preference for a culture that was

178 different to the current one, with a preference for a Clan culture and an increase in

179 Adhocracy with less control, regulation and less focus on outputs. 
180 Combining the two results onto the same plot provides a clear indication of the incongruence

181 between the participant's assessment of the culture now and what would be preferred.

182

183
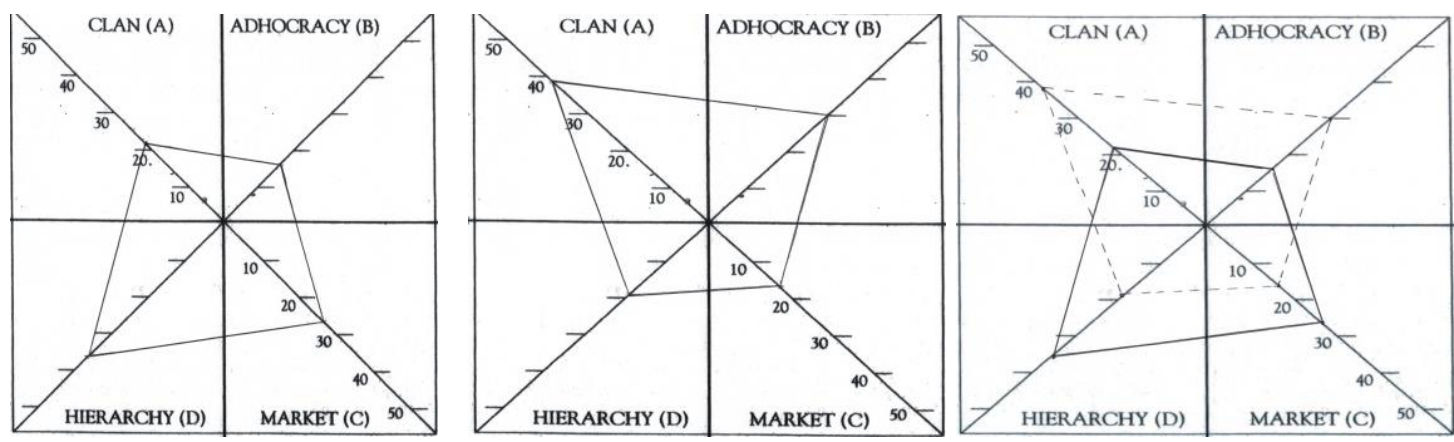

184 Figure 1 CVF Result Now, Preferred and Combined

185 The results of the six dimensions are expressed in Figure 2 as a combined result of the

186 "now" and "preferred" cultures. Each demonstrates incongruence between the predominant

187 cultures "now" to what is preferred. In each dimension there is a preference for an increase

188 in both Clan and Adhocracy cultures with a decrease in both Hierarchy and Market. For a majority of the dimensions there is a difference of greater than ten points. 


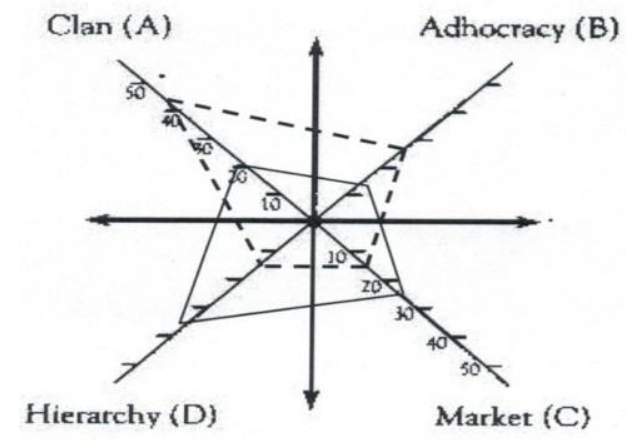

1 Organizational Characteristics

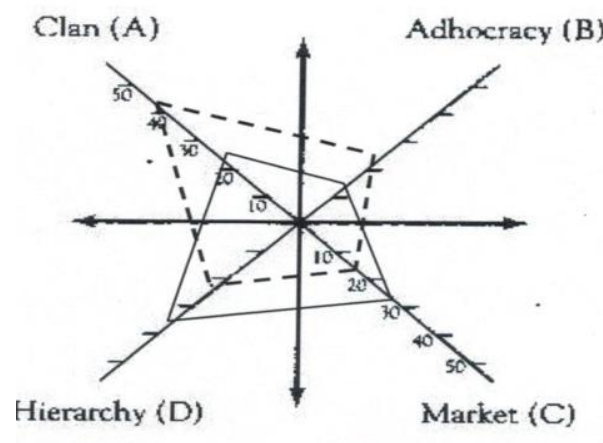

3 Management of Employees

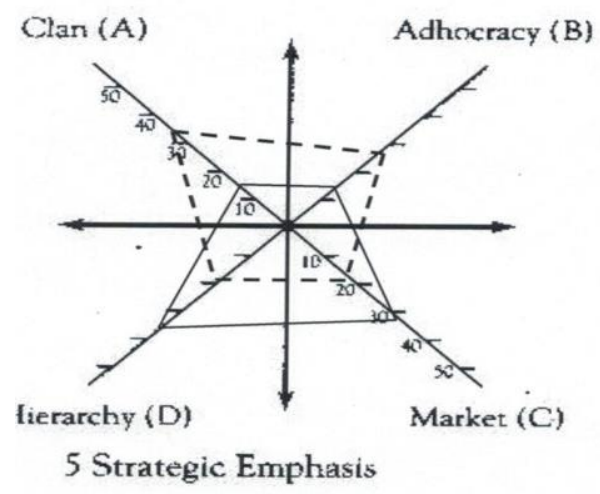

Now $=$

190

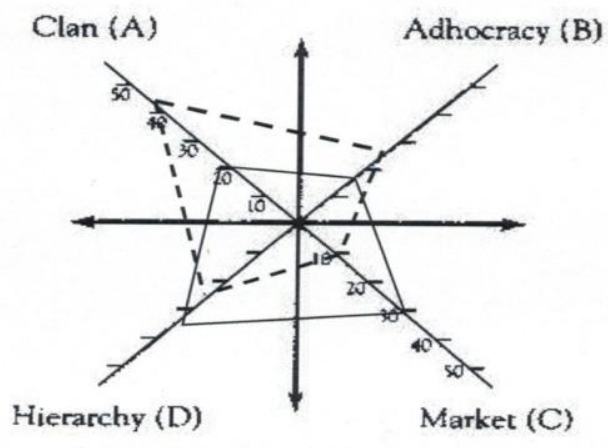

2 Organizational Leader
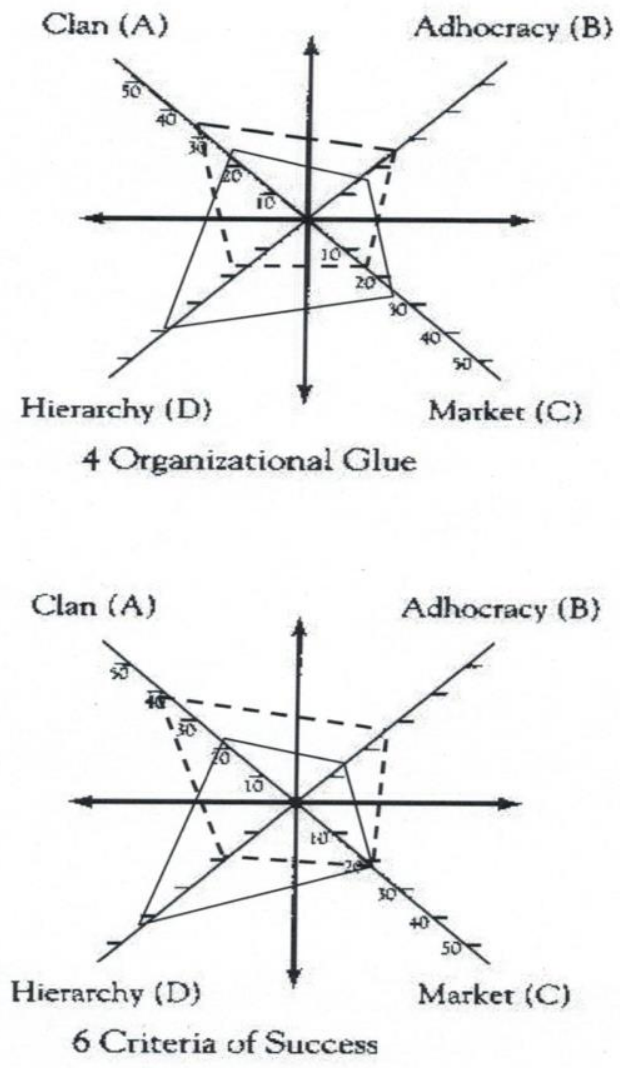

191 Figure 2 CVF Results for six Dimensions, Now and Preferred

\section{Discussion}

193 The response rate to the survey was $26 \%$ and the results must be considered in this context.

194 The predominant culture, as expressed by the results, is the impression of the small

195 percentage of respondents which may limit the inferences that can be drawn. Coincidently, 
196 in the same year another survey was generated by the state government also exploring

197 workplace characteristics and attributes. The research site had a response rate of $18 \%$ with

198 a confidence interval of $3 \%$ which the authors describe as being a representative sample of

199 the facility population ${ }^{38}$. The low response rates may, however, suggest more about the

200 organisation by the silence and non-engagement in the process and is in itself noteworthy.

201 The majority of respondents were those aged $40-50$ years (42\%) and those who had worked

202 for the organisation for $1-5$ years (45\%). Midwives were more likely to respond with $27 \%$ of

203 the potential cohort returning a survey as opposed to $20 \%$ of the obstetricians.

204 The results demonstrated that the majority of the respondents perceived the predominant

205 culture of the organisation to be a hierarchical type with a focus on rules, regulations and

206 control. The Adhocracy culture scored the lowest value of all four culture types. There are

207 opposing values between the two cultures of Hierarchy and Adhocracy which would result in

208 less opportunity for innovation, flexibility or implementation of new ideas in the organisation.

209 Considering the requirement for this organisation to implement significant changes to meet

210 the mandated policy it is important to recognise that the respondents do not perceive there

211 to be an environment that is ready to accept innovation.

212 Market culture scored the second highest and Clan third. The suggestion here is that the

213 maternity service has a focus on meeting performance indicators and target measures, with

214 less focus on collaborative engagements with members of the team who are participating in 
215 the performance. The overall result indicates that at present the characteristics of this

216 maternity unit are not consistent with that of a high performing organisation ${ }^{39}$. That is, an

217 organisation that requires interprofessional collaboration and team work in order to meet

218 performance indicators. As mentioned previously, the inferences that could be drawn from a

219 low response rate is limited, however, those who did respond have stated that there is lack

220 of team work and engagement and if this is prevalent across the service then this may

221 indicate a lack of motivation to be involved in activities including this survey.

222 The results of the hypothetical scoring for the future culture indicated that respondents would

223 prefer an organisation with characteristics that were opposite to that of today. The graph

224 depicts almost a mirror image of the results in the opposite quadrants. Respondents would

225 prefer the organisation to have a collaborative, cohesive team where innovation is

226 encouraged in an environment of flexibility and risk taking. There are greater than ten points

227 difference in each of the quadrant scores between the now and preferred cultures, which

228 according to this framework design, warrants attention. The results demonstrate that there is

229 a need for cultural change within the maternity service if the planned implementation of the

230 government policy is to be successful and sustained.

231 The results also show greater than 10 points difference for each of the six dimensions with a

232 predominance of cultures in the lower quadrants and a preference for the opposite cultures

233 in the future. In each of the dimensions respondents had a desire for the Clan culture which 
234 may indicate the perception of their value to, and within, the organisation. Some of the

235 descriptors for this culture are feelings of teamwork and trust, an orientation towards

236 collaboration and cohesion; a sense of commitment and loyalty where work is done together.

237 If this is the workplace respondents would prefer, then by deduction, this is not how the

238 current environment is viewed.

239 The second preferred culture was Adhocracy with a dynamic and creative workplace where

240 individuality and flexibility is encouraged and a preference to be leaders in innovation. These

241 characteristics were not recognised in their workplace today. The majority of the dimensions

242 have greater than ten points difference between respondents' assessments of the current

243 culture and their preferred culture.

244 The overall results of this study indicate a lack of readiness to change but a strong

245 preference from respondents for the culture to be different. Acknowledging this

246 incongruence and harnessing the desire to be different may influence a change in the

247 culture to one where change is valued. According to Jones et al. in a workplace that is

248 perceived to have strong human relations values (Clan) or open systems values that

249 encourage flexibility (Adhocracy), there are more positive views towards change and a

250 greater willingness to be engaged in change processes ${ }^{39}$. These authors (2005) further

251 describe such an organisation having "reshaping capabilities" that are dynamic and

252 responsive to external need or internal desire. Reshaping capabilities include attributes such 
253 as individual responsiveness, engagement, a commitment to personal and professional

254 development and a willingness to perform. These attributes can positively affect workers'

255 overall competence and thereby increase efficacy in change processes. There is therefore a

256 direct correlation between the reshaping capabilities and the rate of successful change ${ }^{39}$.

257 When reshaping capabilities are low and change is required, such as in the case of the

258 implementation of government policy, organisational tension can develop which can

259 jeopardise the change process. Respondents in this study suggest they do not have a strong

260 sense of trust, cohesion or collaboration in their team. In addition the findings show that

261 respondents believe that there is an under appreciation of their individuality and potential for

262 creative participation in an environment focused on performance. Tension may result from

263 such unmet needs and the inability to meet personal potential can lead to disengagement

264 and reduced efficacy $2,17,32,40-42$.

265 Tensions have also been historically evident in maternity care between obstetricians and

266 midwives where professional boundaries have become territorial and fiercely contested ${ }^{25,43-}$

26745 . In Foucauldian terms, the scientific knowledge of childbirth was traditionally held by

268 obstetricians and hence professional power was held by them to the exclusion of other

269 disciplines and in particular midwifery ${ }^{46}$. Reforms in maternity care in recent times, however,

270 have resulted in changes in the roles and responsibilities for maternity carers. These

271 changes have been most evident with the development of midwifery-led models of care with 
272 midwives regaining the responsibility for women of normal risk and collaborating with

273 obstetricians where risk is identified. Despite sound evidence for the effectiveness of

274 midwifery-led models of care, ${ }^{47,48}$ the translation into practice and the transition to

275 collaborative models of care continues to be challenged by the inability, or reluctance, to

276 relinquish, or modify, former roles and responsibilities ${ }^{25,45,49-51}$.

277 Appreciating the existence of historical tensions between healthcare teams and the

278 difficulties with translation of evidence into practice, gaining an understanding the

279 predominant culture of an organisation and its readiness for change is critical. Such

280 knowledge will enable decision makers to design appropriate strategies so that change can

281 be effectively implemented. For this midwifery service the follow up plan is for an action

282 research project where the clinicians will be invited to contribute to the development of

283 strategies to implement the government policy. Respondents have nominated that they

284 would prefer to be included in teamwork, they would prefer to have the opportunity to be

285 creative and to develop new ideas and that they would like some direction but not to be

286 overly controlled. The cyclical nature of action research methodology may be the key to the

287 successful implementation of this government policy.

288 It is not possible to determine whether behaviours or organisational characteristics require

289 change if there has been no measurement of the current situation. The CVF provides a way

290 of measuring a baseline; the information can then be used to design interventions to 
291 influence the desired changes. The CVF tool would then be used to reassess the

292 predominant and preferred culture over time. It is not possible to report on changing culture

293 in the research site here as the processes leading towards changing the culture are

294 continuing. What this paper offers is a way forward for maternity clinicians facing one of the

295 most common challenges in practice.

\section{Conclusion}

297 In healthcare systems where interprofessional collaboration is not evident and where

298 tensions continue between professional boundaries of responsibility there is a threat to the

299 delivery of safe and effective care. In order to change what may be an historical legacy of

300 hierarchical structures there first needs to be recognition of the situation; an intention to

301 change the status quo and then purposeful strategies to support change towards

302 interprofessional collaboration.

303 The CVF is a valuable tool to assess the predominant culture of an organisation as part of

304 preparatory work prior to the implementation of change to increase the opportunity for

305 success.

306 Limitations

307 The response rate to this process was lower than anticipated and the results may not be an

308 indication of the overall assessment of the predominant culture.

309 Acknowledgements 
There has been no financial assistance received for this work.

\section{References}

312 1. Greenhalgh T, Robert G, MacFarlane F, Bate P, Kyriakidou O. Diffusion of

313 innovation in service organisations: Systematic review and recommendations. The Milbank

314 Quarterly 2004; 82(4): 581-629.

315 2. Weiner BJ. A theory of organizational readiness for change. Implementation Science:

316 IS 2009; 4: 67-.

317 3. Blackman D, O’Flynn J, Ugyel L. A Diagnostic Tool for Assessing Organisational

318 Readiness for Complex Change. Australian and New Zealand Academy of Management.

319 Hobart; 2013.

320 4. Dopson S, Fitzgerald L, Ferlie E. Understanding Change and Innovation in

321 Healthcare Settings: Reconceptualizing the Active Role of Context. Journal of Change

322 Management 2008; 8(3): 213-31.

323 5. Igo T, Skitmore M. Diagnosing the organizational culture of an Australian

324 engineering consultancy using the competing values framework. Construction Innovation 325 2006; 6: 121-39.

326 6. Lakos A, Phipps S. Creating a culture of assessment: a catalyst for organizational 327 change. Libraries and the academy 2004; 4(3): 345-61.

328 7. Miller D. Building sustainable change capability. Industrial and Commercial Training 329 2004; 36(1): 9-12.

330 8. Nazir N. Person-culture fit and employee committment in banks. Vikalpa 2005; 30(3): $331 \quad 39-51$.

332 9. Yong K, Pheng L. Organizational culture and TQM implementations in construction

333 firms in Singapore. Construction management and economics 2008; 26: 237-48.

334 10. Fawcett S, Brau J, Rhoads G, Whitlark D. Spirituality and organizational culture:

335 cultivating the ABCs of an inspiring workplace. International Journal of Public

336 Administration 2008; 31: 420-38.

337 11. Hemmelgarn A, Glisson C, James L. Organizational culture and climate: Implications

338 for services and interventions research. Clinical Psychology: Science and Practice 2006;

339 13(1): 73-89.

340 12. Allen R, Kraft C. Discovering your hospital's unconscious. Hospital Forum 1983;

341 (January/february): 11-7.

342 13. Allen R, Kraft C. Transformations that last: a cultural approach. Alexandria,

343 Vancouver: Miles River Press; 1984. 
344 14. Linnenluecke M, Russell S, Griffiths A. Subcultures and Sustainability Practices: the

345 Impact on Understanding Corporate Sustainability. Business Strategy and the Environment $346 \quad 2007 ; \mathbf{1 0}$.

347 15. Rogers E. Diffusion of Innovations. 5th ed. New York: Free Press; 2003.

348 16. Armenakis A, Harris S. Crafting a Change Message to Create Transformational

349 Readiness. . Journal of Organizational Change Management, 15(2), 169-83 2002; 15(2):

$350 \quad 169-83$.

351 17. Paré G, Sicotte C, Poba-Nzaou P, Balouzakis G. Clinicians' perceptions of

352 organizational readiness for change in the context of clinical information system projects:

353 insights from two cross-sectional surveys. Implementation Science 2011; 6(15): 1-14.

354 18. Cameron S, Quinn R. Diagnosing and Changing Organisational Culture: based on the 355 Competing Values Framework. San Francisco: : Jossey-Bass; 2006.

356 19. Department of Health NSW. Towards Normal Birth. In: Primary \& Community

357 Partnerships Branch Department of Health NSW, editor. Sydney; 2009.

358 20. Centre for Epidemiology and Evidence. New South Wales Mothers and Babies 2010.

359 In: Population and Public Health Division, editor. Sydney: NSW Ministry of Health; 2012.

360 21. Lee Y, Roberts C, Patterson J, et al. Unexplained variation in hospital caesarean 361 section rates. MJA 2013; 199: 348-53.

362 22. Women's Healthcare Australasia. Benchmarking Maternity Care Individual Report

363 2012/13. Canberra, Australia, 2014.

364 23. Simpson K, James D, Knox G. Nurse-physician communication during labour and

365 birth: implications for patient safety. Journal Obstetrics Gynaecology Neonatal Nursing

$3662006 ; 35$ : 547-56.

367 24. Downe S, Byrom S, Finlayson K, Fleming A, Edge E. East Lancashire Childbirth

368 Choices Project: Choice, safety and collaboration. Lancashire, England.: University of

369 Central Lancashire 2009.

370 25. Hastie C, Fahy K. Inter-professional collaboration in delivery suite: A qualitative 371 study. Women and Birth 2011; 24(2): 72-9.

372 26. Monari F, Di Mario S, Facchinetti F, Basevi V. Obstetricians' and midwives' attitudes 373 toward cesarean section. Birth 2008; 35(2): 129-35.

374 27. Australian Department of Health and Aging. Improving Maternity Services in

375 Australia The Report of the Maternity Services Review. In: Australian Government

376 Department of Health and Ageing, editor. Canberra: Commonwealth of Australia; 2009.

377 28. Kvarnstrom S. Difficulties in collaboration: A critical incident study of

378 interprofessional healthcare teamwork. Journal of Interprofessional Care 2008; 22(2): 191379203. 

Obstetric Patient Safety in Three Academic Facilities. JOGNN: Journal of Obstetric,

382 Gynecologic \& Neonatal Nursing 2013; 42(5): 606-16 11p.

383 30. Kear T, Ulrich B. The role of interprofessional collaboration in supporting a culture of safety. Nephrology News \& Issues 2015; 29(8): 21.

31. Wheelan S, Burchill C, Tilin F. The link between teamwork and patients' outcomes in intensive care units. American Journal of Critical Care 2003; 12: 527-34.

32. Kennedy H, Lyndon A. Tensions and teamwork in nursing and midwifery relationships. Journal Obstet Gynecol Neonatal Nurs 2008; 37(4): 426-35. Successful Hospital Innovation. The Innovation Journal: The Public Sector Innovation Journal 2012; 17(1).

34. Reina M, Reina D, Rushton C. Trust: The Foundation for Team Collaboration and Healthy Work Environments. AACN Advanced Critical Care 2007; 18(2): 103-8. intervention to improve interprofessional collaboration and communications: A comparative qualitative study. Journal of Interprofessional Care, 2010; 24(4 ): 350-61. organizational culture in health care: a review of the available instruments. Health Services Research 2003; 38(3): 923-45.

37. Helfrich C, Li1 Y, Mohr D, Meterko M, Sales A. Assessing an organizational culture instrument based on the Competing Values Framework: Exploratory and confirmatory factor analyses. Implementation Science 2007; 2(13): 1-14. 38. ORC International. 2011 YourSay Workplace Survey. 2011. 39. Jones R, Jimmieson N, Griffiths A. The Impact of Organizational Culture and Reshaping Capabilities on Change Implementation Success: The Mediating Role of Readiness for Change. Journal of Management Studies 2005; 42(2): 361-86. networks of health care professionals: implications for the design of dissemination strategies.

\section{Social Science \& Medicine 1999; 48(5): 633-46.}

410 41. Veronesi J. Is your workforce engaged to be satisfied? Home Health Care

411 Management \& Practice 2009; 21(2): 124-6.

412 42. Manley K. 'The way things are done around here'-Developing a culture of

413 effectiveness: A pre-requisite to individual and team effectiveness in critical care. Australian 414 Critical Care 2008; 21(2): 83-5.

415 43. Benoit C, Zadoroznyj M. Medical dominance and neoliberalisation in maternal care 416 provision: the evidence from Canada and Australia. . Social Science \& Medicine 2010; 71: $417 \quad 475-81$. 
418 44. Vernon L. A Brief Overview of How Male Medicine Co-Opted the Midwife's Role in 419 the Birth Process Open Journal of Nursing 2015; 5: 758-64.

420 45. Reiger K, Lane K. Working together: collaboration between midwives and doctors in 421 public hospitals. Australian Health Review 2009; 33(2): 315-24.

422 46. Foucault M. Power/knowledge: Selected interviews and other writings 1972-77. New 423 York: Pantheon Books; 1980.

424 47. Sandall J, Soltani H, Gates S, Shennan A, Devane D. Midwife-led continuity models 425 versus other models of care for childbearing women. . Cochrane Database of Systematic 426 Reviews Wiley; 2016.

427 48. Tracy S, Hartz D, Tracy M, et al. Caseload midwifery care versus standard maternity 428 care for women of any risk: M@NGO, a randomised controlled trial. Lancet 2013; 382

429 (9906): 1723-32 10p.

$43049 . \quad$ Lane K. The plasticity of professional boundaries: A case study of collaborative care 431 in maternity services. Health Sociology Review 2006; 15(4): 341-52.

432 50. Newnham E. GENERAL SECTION: Midwifery directions: The Australian maternity 433 services review. Health Sociology Review 2010; 19(2): 245-59.

434 51. Newnham E. Birth control: Power/knowledge in the politics of birth. Health 435 Sociology Review 2014; 23(3): 254-68.

436 